\title{
МАРК РИШИР
}

\section{ФЕНОМЕНОЛОГИЯ ПОЭТИЧЕСКОГО ЭЛЕМЕНТА}

\section{РОМАН СОКОЛОВ (пер. с фр.)}

Кандидат философских наук, доцент кафедры Общеобразовательных дисциплин, Чувашская государственная сельскохозяйственная академия, 428003, Чебоксары, Россия.

E-mail: raymondq@mail.ru

\section{ГЕОРГИЙ ЧЕРНАВИН (ред.)}

$\mathrm{PhD}$, доцент, Национальный Исследовательский Университет - Высшая Школа Экономики, 105066 Москва, Россия.

E-mail: gchernavin@hse.ru

\section{MARC RICHIR}

\section{PHENOMENOLOGY OF THE POETIC ELEMENT}

\section{ROMAN SOKOLOV (trans.)}

$\mathrm{PhD}$, associate professor, Department of General Education Disciplines, Chuvash State Agricultural Academy, 428003 Cheboksary Russia.

E-mail: raymondq@mail.ru

\section{GEORGY CHERNAVIN (ed.)}

PhD, Assistant Professor, National Research University - Higher School of Economics, 105066

Moscow, Russia.

E-mail: gchernavin@hse.ru

1 Этот очерк подводит итог текущей работе, предварительно названной нами «Феноменологические фрагменты о языке» (Richir, 2008).

(C) ROMAN SOKOLOV, TRANS., 2016

(C) GEORGY CHERNAVIN, ED., 2016 
Термин «перцептивная» фаvтабіа (perzeptive Phantasie), введённый Гуссерлем в тексте №18 XXIII тома Гуссерлианы, обозначает тот особый

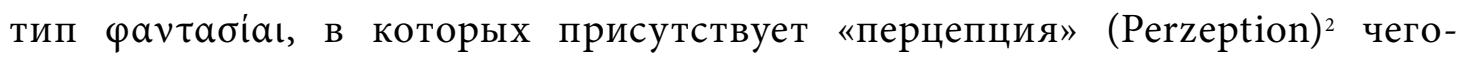
то такого, что находится по ту сторону (или за пределами) как реального, так и фиктивного. «Перцепция» выходит за рамки как воспринимаемого в восприятии (Wahrnehmung), так и интенционального объекта воображения, возникающего в том случае, когда есть наглядное изображение воображаемого объекта, «перцептивная» видимость, некий образ-объект, Bildobjekt, который в действительности является симулякром. Типичный пример этого - театральный персонаж, которого «воплощает» актёр. В самом деле, хотя роль играет актёр, фантазийно «перципированным» на сцене, в неком ином театральном «пространстве» оказывается именно Ричард III. [Персонаж находится] по ту сторону восприятия (Wahrnehmung) тела актёра и произносимых им слов, и даже по ту сторону, пробуждающего наше воображение «перцептивного» облика героя, который, казалось бы, зависит от актёра. Весь талант актёра состоит в том, чтобы своей игрой (жестами, мимикой, речью - тем, что реально происходит с его живым телом, Leibkörper) перенести зрителей в иное театральное «пространство», в вымысел или театральную иллюзию. Реальная сцена (с её декорациями) и реальный актёр (с его реальным телом и реальными костюмами) не рассеиваются в воображаемом. Само это реальное, перейдя в фаvтабі́, превращается в вымысел реального, изобразительное содержание которого то же, что и в восприятии, но оно «воспринимается» и в фаvтабіa, которая ирреализует и нейтрализует его. Иначе говоря, так «перципированное» «реальное» находится в бесконечном переходном положении между реальностью, которая могла бы отменить театральное представление, и «фантастическим» (а не воображаемым). ${ }^{3}$

2 Далее мы будем переводить «Perzpetion» как «perception» с кавычками (которые также указывают на производное «perzeptiv») и Wahrnehmung как perception без кавычек.

3 Ришир исходит из гуссерлевского противопоставления фантазии и воображения, которое у самого Гуссерля не было вполне прояснённым. Французский философ рассматривает воображение как представление объекта посредством его образа. Иными словами, он видит в воображении «репрезентативный акт». Напротив, фантазия у него не имеет ничего общего с репрезентацией. Более того, в отличие от имагинативного акта, акт фантазии даже не является интенциональным. Он понимается 
«Реальное» схватывается в «фантастическом», т.е. оно в нем «воспринято», заставляет его участвовать в представлении. Изображение «реального» тем самым присутствует и в «перцептивной» фаvтабі́, как абстрактная часть конкретного целого, конституированного «перцептивной» Парадоксально, что другой абстрактной частью будет «перцепция» безо́бразного (в театре - воплощаемый актёром герой). Поэтому, поскольку «реальное» находится в переходном положении между «реальностью»и «фантастикой», его можно назвать переходным (transitionnel) (в терминах Винникота). Таким образом, талант актёра заключается в том, чтобы самоустраниться перед лицом своего персонажа или в нем, т. е. в том, чтобы путем [актёрской] игры, самому стать переходным. Иначе говоря, он по-настоящему играет свою роль не тогда, когда «подражает» (mimétise) воображаемому представлению или зеркально отражает сложившееся у него представление о персонаже. Иначе это было бы чем-то вроде механического удвоения в рамках окружающего мира, Umwelt, выступающего лишь «обрамлением»; но в созерцании представленного «образа», как заметил ещё Дидро, герой отсутствует. Актёр по-настоящему играет только если «чувствует» своего героя, т. е. если «совершает», прежде всего для себя, это парадоксальное вчувствование (Einfühlung) в персонаж, не существующий вне театрального представления. Он по-настоящему играет, только если самоустраняется (устраняет то, каков он для себя как Leibkörper, тело, и как Leibhaftigkeit, аффективность - в этом и состоит работа над ролью) в пользу этого Einfühlung настолько, что «передаёт» зрителям это Einfühlung. Если зрители вовлечены в спектакль, то они осуществляют Einfühlung в отношении Einfühlung осуществленного актёром.

Поэтому можно согласиться с тем, что Einfühlung в другого в действительности - это не восприятие (вещи) и не воображение (объекта). Оно совершается в фаvтабіа и благодаря ей (что заставляет нас говорить о фантазийном теле, Phantasieleib); более того, это «перцептивная» фаvтабі́ близости (intimité) другого, которую нельзя образно представить в (перцептивном и/

здесь как «прото-онтологический» и «архитектонический» процесс. (Подробнее см.: Detisova, 2012). Прим. пер. 
или имагинативном) созерцании. В случае театра, если актёр самоустраняется, то он становится посредником вчувствования (Einfühlung) в воплощённого им персонажа. Переход (le passage), который происходит путем такого самоустранения в опосредовании, - это в некотором роде переход целостной

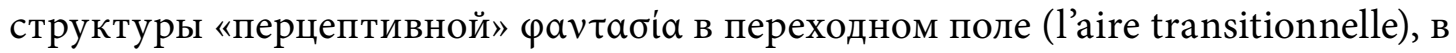
смысле Винникота. ${ }^{4}$ Таким образом, в этой перспективе, театральная ситуация имеет следующий смысл: актёр «перципирует» в не имеющего образа в каком бы то ни было созерцании. Актерской игрой жестами, мимикой, интонациями речи - он вызывает эту «перцептивную»

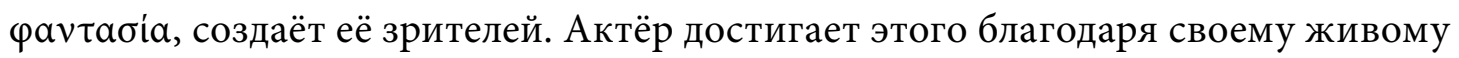
телу (Leibkörper), которое становится «фантастическим» или, точнее, переходным телом, благодаря игре его живой телесности (Leiblichkeit) и его фантазийной телесности (Phantasieleiblichkeit). Зрители «воспринимают» Ричарда III в фаvтабі́a на сцене, при этом сама сцена уже «перципирована» в фаvтабі́a. К этому надо добавить, что такая безо́бразность (в созерцании) близости персонажа, т.е., если хотите, невидимость этого последнего, не имеет ничего общего с классической безо́бразностью умопостигаемого: персонаж не является идеальностью или идеей в платоновском смысле. Вот почему, чтобы избежать всякой двусмысленности, мы говорим здесь о безо́бразности, уточняя, что она также «перципирована» в

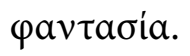

Случай театра можно легко распространить на всё поле эстетики, включив в него живопись, музыку, поэзию и роман. В каждом случае можно найти некий «объект», который воспринимается как переходный, и некое безо́бразное, «перципированное» в той же самой «перцептивной» фаvтабі́. Что касается переходного «объекта», то в случае живописи это воображаемый образсюжет, Bildsujet (который, вероятно, сам по себе может быть нефигуративным), опирающийся на образ-объект, Bildobjekt, который, в свою очередь, опирается

\footnotetext{
4 Под «переходным полем» Винникотт понимает «иллюзорное» пространство первичной коммуникации, в котором осуществляется связь не просто между младенцем и его матерью, но, прежде всего, между «внутренней» и «внешней» реальностями, и формируется способность субъекта конституировать себя (свою телесность) в двойной перспективе: своего собственного внутреннего опыта и фантазийно «воспринятого» опыта другого, в зеркале которого он узнаёт самого себя. - Прим. nер.
} 
на физический носитель. В случае музыки это издаваемые инструментами звуки или группы звуков (которые ео ірsо и исполняют); в романе это Bildsujets, весьма неполно изображенные в описаниях и ситуациях. Наконец, в случае поэзии это более-менее образные (figuratifs) элементы означаемого, которые приводятся в действие словами и игрой слов. Отсюда в каждом случае следует, что безо́бразный компонент «перцептивной» $а л \tau \alpha \sigma i \alpha$ относительно безразличен к изображению (la figuration) взятого в фаvтабía переходного «объекта». Этот «объект» укоренён не только в (зависящей от художника) фактуре произведения, но и в качестве его созерцания, слушания или чтения, а также - в качестве его исполнения (если, как в данном случае, оно имеет место). Эти два качества, по Винникотту, имеют отношение к свободе «свободной игры» (без заранее установленных правил); такая игра разыгрывается всякий раз, как мы оказываемся в переходном поле. И, как мы видели, переходное не обязательно совпадает с «перципированным» в фаvтабі́ реальным, оно может соскальзывать и к воображаемым «представлениям». Вот почему переход не имеет конца, он не ограничен заданными пределами некого интервала.

Основной парадокс «перцептивной» фаvтабі́ $а$ состоит, таким образом, в том, что через относительно тонкую или грубую образность (la figurabilité) переходного «объекта», «перципированного» в фаvтабі́, через посредничество образности особо рода, также «воспринимается» нечто радикально безо́бразное, лишенное всякого перцептивного или имагинативного созерцания и конституирующее своего рода переходную «глубину» и «размытость» «объекта». (При этом, в случае

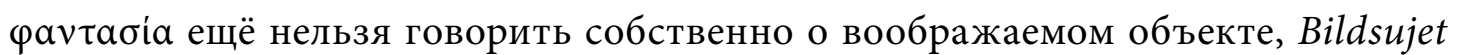
как таковом, т. е. строго намеченном в определённой интенциональности, которая скрывала бы безо́бразное и упраздняла переходное.) И, если вернуться к вчувствованию (Einfühlung), то со взглядом другого (пробуждающим мой взгляд) дело обстоит так же. Через образность лица другого и живую телесность (la Leibkörperlichkeit) другого я могу «почувствовать» (fühlen) внутренне. Но [это возможно] лишь потому, что посредником выступает зазор (в хоре, в смысле платоновского Тимея) как пространственное и временное ничто, трепещущая и живая «сердцевина» другого. Я могу «ощутить» себя другим по отношению к этому другому в преобразовании этого зазора в темпорализующий (в языке) 
и спациализирующий ${ }^{5}$ зазор (оба зазора абсолютны, будучи «обителью» хоры). В сущности, я «перципирую» в фаvтабі́а в «сердцевине» живого взгляда

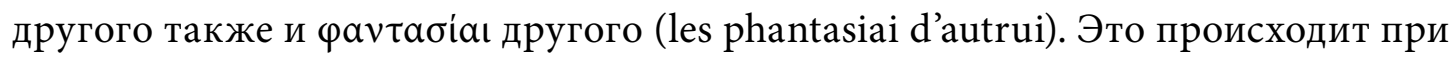
посредничестве тех аффицирований, которые я испытываю как изменяющиеся в своих нескончаемых поворотах; среди них кружатся в танце виртуально

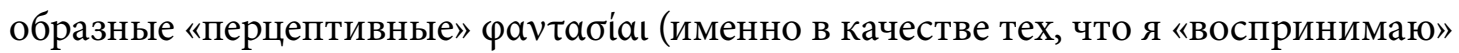

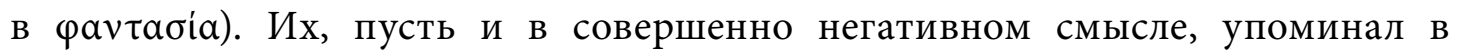
Иенской реальной философии (1805) Гегель. ${ }^{7}$ В терминах Винникотта, общая

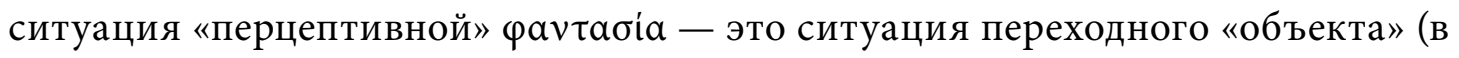

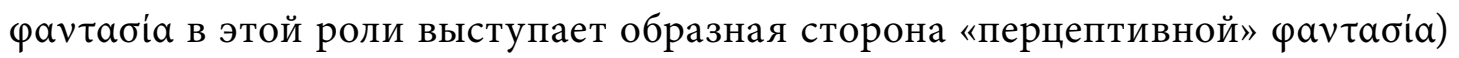
в квази-онейрическом ${ }^{8}$ поле. Такое переходное поле - это поле игры без

\footnotetext{
5 Речь здесь идёт об особой модификации опыта телесности, который понимается у Ришира не просто в смысле гуссерлевского «kinaesthesis», связанного с проблемой темпоральности сознания и пассивного синтеза, но и исходя из примата фантазии и аффективности над восприятием и ощущением. Отсюда его отсылки к платоновской хоре (рассматриваемой им как некий «носитель пространственности», «вместилище без формы», которое, однако, в отличие от хоры Платона обладает собственным генезисом) и ко взгляду другого как условиям первичной телесной самоидентификации. И то, и другое выступает здесь в качестве различных модусов «бесформенного» (безо́бразного), к которым, помимо «фантазийной телесности» и "другого, который смотрит на нас», относится также сам «фантазийный объект», предстающий перед нами в периептивной фантазии в качестве «реального симулякра» (поскольку он, так сказать, располагается по ту сторону конкретного имагинативного содержания образа). На стадии первичной, внеязыковой феноменальности ришировский «индивид» как бы слит с этим «бесформенным», образуя, благодаря «сгущению аффективности, происходящей путём кинестетического напряжения и расслабления», «трансцендентальное лоно», но по мере феноменализации посредством языковой способности формируется зазор внутри этого первоначального единства, подготавливая его последующую поляризацию фигурами «меня самого» и «другого». - Прим. пер.

6 «B-третьих, есть еще один род, а именно пространство ( $\chi \omega \dot{\rho} \alpha)$ : оно вечно, не приемлет разрушения, дарует обитель (ह̌ $\delta \alpha)$ всему роду, но само воспринимается вне ощущения, посредством некоего незаконного умозаключения, и поверить в него почти невозможно. Мы видим его как бы в грезах...» (Platon, 1994, Timei 52a8-b2). Вслед за Платоном Ришир говорит о хоре как об обители (Тимей 52b1) или пристанище (Тимей 53а2), подразумевая при этом «абсолютное здесь» Гуссерля, но понимает его, очевидно, лишь как один из полюсов первичного (допредикативного) опыта сознания, который «перемигивается» с фантазийным и бесформенным «трансцендентальным лоном», образованным «совокупностью» (Флориан Форестье) младенца и его матери. При этом «трансцендентальное лоно» выступает как «повёрнутое» абсолютное здесь. - Прим. пер.

7 См.: Hegel, Jenenser Realphilosophie, Subjektiver Geist, a. Intelligenz, J. Hoffmeister (Hrsg.), Meiner, Philosophische Bibliothek, Bd. 67, pp. 180 - 181 (Hegel, 1967).

8 В психоанализе Винникотта «переходное поле» - это пространство, в котором происходит формирование символического, постепенно отделяющегося от реального. Однако в своём первоначальном смысле конституирующийся в этом поле «переходный объект» совмещает в себе (без их различения) черты фантастического и фактического, внутреннего и внешнего, творческого и воспринимаемого, субъективного и объективного. Очевидно, именно поэтому Ришир называет такое поле «квазионейрическим». - Прим. пер.
} 
правил, на котором разыгрывается трансцендентальная интерфактичность. ${ }^{9}$ Интерфактичность, в крайнем случае, может быть чисто виртуальной, ${ }^{10}$ что не мешает ей всегда функционировать, а значит - составлять один из компонентов радикально безо́бразного. Итак, мы видим, что «перцептивная» фаvтабía в её образности подразумевает «воспринятое» в ней радикально безо́бразное совсем не интенциональным образом, ведь иначе это было бы воображение или восприятие образного объекта или же отсылка «в пустоту». Разумеется, в этой парадоксальной структуре нет ничего позиционального ${ }^{11}$ или квази-позиционального (пригодного для бытийного полагания без преобразования), а значит, здесь в принципе нет ничего пригодного для онтологии; впрочем, отсюда вовсе не следует, что это «ничего» ни на что не влияет. На деле следствия этой ситуации сложны и многообразны.

Те следствия, которые нам хотелось бы извлечь отсюда в первую очередь, касаются речевой деятельности (langage). В нашем случае это следствие касается мышления, поскольку мы принимаем, что всякое мышление - это мышление в рамках речевой деятельности и что язык (langue), со всеми его правилами и способами выражения, есть лишь малая часть того, что подчинено символическому учреждению. Поэтому нам надо, оттачивая наше описание, вернуться к тому, с чего мы начали.

\footnotetext{
9 Трансцендентальная интерфактичность - один из ключевых концептов феноменологии Ришира: некое первичное, доинтенциональное отношение, устанавливающееся между взглядом матери, идентифицируемым как одно из «абсолютных здесь», и «взглядом младенца» как другим «абсолютным здесь». Это отношение конституируется на уровне «архаических здесь» Leiblichkeit, а затем переносится «во внешние друг для друга места» (Форестье), благодаря чему происходит переход от доинтенциональной трансцендентальной интерфактичности к интенциональной трансцендентальной субъективности. Прим. пер.

10 Под виртуальным мы, почти как в квантовой механике, понимаем то, что, не будучи ни актуальным, ни связанным с актуальным при посредстве потенциального, оказывает не меньшее влияние на реальную действительность в феноменологическом поле. Поэтому виртуальное существует в смысле «специфического» сверхвозможного, заставляя трепетать структуры актуальности, когда виртуальное «функционирует» (fungiert в словаре Гуссерля).

${ }^{11}$ В словаре Гуссерля это «относящееся к Seinssetzung», в словаре Сартра - тетическое, т. е. относящееся к интенциональному акту сознания, полагающего свой предмет в качестве имеющего какое-то отношение к бытию (существующего, несуществующего, присутствующего, отсутствующего, сомнительного, приостановленного и т. д.). Противоположностью тетического акта будет формальный акт, т. е. полагающий свой предмет безотносительно к бытию. - Прим. пер.
} 
«Перцепция» переходного «объекта» фактически представляет собой Schein-Perzeption, видимость «перцепции»; прежде всего «перципированной» здесь оказывается та вещь (Sache), которую этот «объект» неинтенционально подразумевает - в этом часть парадокса «перцептивной» фаvтабі́. Действительно,

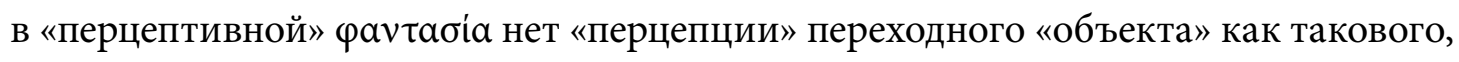
иначе такая «перцепция» стала бы восприятием (Wahrnehmung), а «объект» утратил бы свой переходный статус. Именно это имеет в виду Гуссерль, когда (опять же, в Нua XXIII, текст №18) объясняет, что «перципировать» [в фантазии - значит] «отклоняться». Речь идёт о том, чтобы сразу «перцепировать» весьма особую фикцию (fictum), в которой объект, будучи образным (figuré), не является изображением (figuration) в Bildobjekt некого Bildsujet. Переходный объект - это не «образ», а особая фикция, которая не противостоит реальности (Realität). Мы, в свою очередь, можем сказать, что эта фикция происходит не из модификации в воображении (с помощью квази-полагания), а из модификации в фаvтабі́. Именно эта последняя «перцептивна», а это значит: с одной стороны, в изображении переходного «объекта» нет ничего интенционального или, в более узком смысле, семиотического; с другой стороны, эта модификация с самого начала предполагает приостановку [бытийной значимости] в «фикции» фаvтабіа. Модификации в

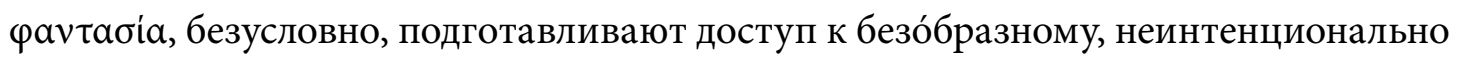
его подразумевая, но при этом фактически самоустраняются перед ним. Это собственно и «перципируется» (что парадоксально). Речь при этом вовсе не идёт об онтологическом тождестве переходного «объекта» и того, к чему он открывает доступ. Кусочек ткани, который сосёт грудной младенец, неинтенционально подразумевает мать, и она, в некотором смысле, в нём «есть», но он не является ни матерью, ни её символическим представлением. И именно потому, что мать как таковая гораздо больше всего того, что может происходить в наглядном изображении, что ей присуща некая, сама по себе безо́бразная, вещественность (Sachlichkeit) (то, что мы называем трансцендентальным «лоном»), она и может быть в каком-то смысле «обретена» в посасывании кусочка ткани.

Итак, выделить переходный «объект» - значит выстроить или произвести 
(безусловно, необходимую) аналитическую абстракцию, которой, однако, нет в феноменологической вещественности-содержательности, Sachlichkeit

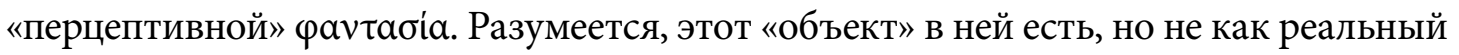

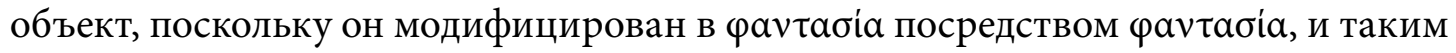
образом, его изображение оказывается фиктивным, так как не изображает ничего, кроме, так сказать, безо́бразного. «Перципированное»в фаvтабі́ не явлено как Bildsujet и тем не менее оно там, но уже как безо́бразное в фаvтабі́. Если хотите, оно «явлено» в «перцептивной» фаvтабі́ как безо́бразное. Можно даже

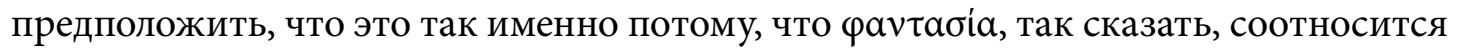
прежде всего с безо́бразным и, чтобы «стабилизировать» это отношение, она «избирает» некий «объект», который всегда уже «фиктивен» (хотя и действителен). Этот «объект» всегда уже в фаvтабіа, а значит, всегда уже модифицирован

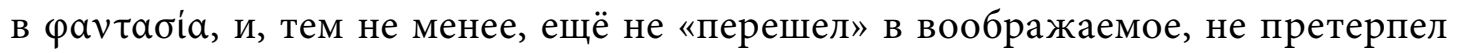
учреждения, Stiftung, в воображении.

Между тем это предполагает некую самость и, как кажется, некий выбор. Первое предположение подразумевает скрытую работу феноменологического возвышенного «в действии», т. е. сверхсгущение аффективности в некую самость. Затем оно, как минимум, подразумевает схематическое прерывание феноменологически слепого схематизма внеязыковых феноменов, ${ }^{12}$ а значит всегда переход от феноменологического схематизма к схематизму языковому, который есть не что иное, как его продолжение. Второе предположение не подразумевает ни бессознательного «выбора объекта» во фрейдовском смысле, ни свободы произвольного выбора. Открытость к безо́бразному матери, при этом строго совпадает с «обнаружением» переходного «объекта». Именно в этом вся его ценность: в слиянии выделений и запахов младенца (примордиального) с выделениями (молока) и запахами матери (в слиянии, благодаря которому, «объект» неинтенционально подразумевает «трансцендентальное лоно»). (Не говоря уже о том, что между кусочком ткани и грудью матери действительно есть некоторые внешние, наблюдаемые сходства и они могут направлять выбор). Всё это происходит

${ }^{12}$ См., например, наши Méditations phénoménologiques, Jérôme Millon, Coll. «Krisis», Grenoble, 1992 (Richir, 1992). 


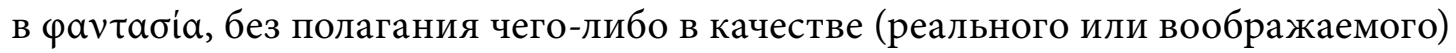
сущего, хотя и в некой вещественности (une Sachlichkeit), которую разделяет и мать (если она не настолько безжалостна, чтобы отнять кусочек ткани у ребёнка).

Разумеется, трансцендентальный генезис не останавливается лишь на этой,

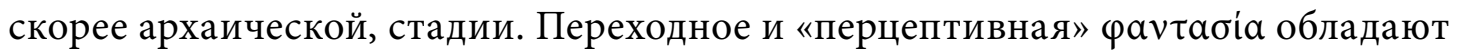
бесконечной способностью к расширениям и метаморфозам. Прежде всего это касается обмена взглядами, впрочем, к этой теме мы будем обращаться лишь по мере необходимости. В данном случае, это более чем оправдано. Взгляд, пробуждаемый взглядом (матери), на деле уже находится там, в некой

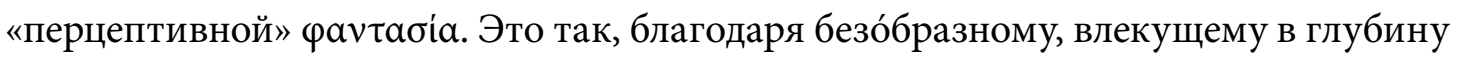
зрачков (т. е. - уже переходного «объекта»); оно кроется в глазах [матери], наблюдающих за пробуждением взгляда [младенца]. А значит, точно так же, в

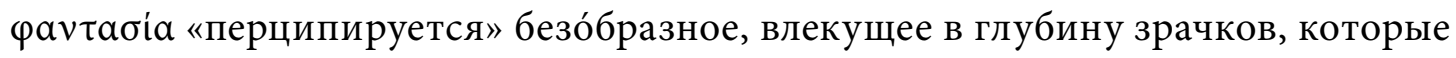
отныне «обретают жизнь», наблюдают и не кажутся слепыми. Глаза и физические очертания лица здесь «фиктивны», хотя они все ещё относятся к действительности, т. е. они с самого начала претерпевают модификацию в фаvтабі́. Это, конечно, касается того, что собственно и происходит при обмене взглядами, поскольку «физикализация» или объективация лица придаёт ему неподвижность. Объективация взгляда делает его подобным взгляду статуй, он становится слепым или пустым и, следовательно, исчезает. Так, мы можем подавить взгляд другого, заглянув ему «прямо в глаза»: не следя за его взглядом, а фокусируясь на его глазах.

Такая ситуация, при всей своей необычности (она скорее парадоксальна), тем не менее парадигматична, поскольку выступает как матрица или элементарная

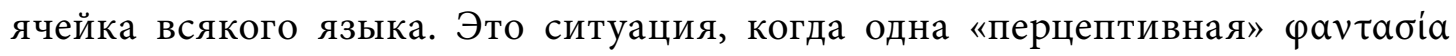
«перцепирует» иную «перцептивную» фаvтабіа. Понятно, что инаковость здесь взаимна - это инаковость двух абсолютных здесь в качестве двух «обителей» (живых тел, Leiber) хоры, т.е. для нас речь идет о живой телесности, Leiblichkeit (и Phantasieleiblichkeit). Под хорой мы понимаем здесь «ещё не» пространство, a, так сказать, схематизирующее и схематичное разрастание ${ }^{13}$ элементарной

\footnotetext{
${ }^{13}$ Конституирование пространства как «системы мест или как внешней локализации» происходит параллельно учреждению Leibkorper (телу как интенциональному центру и, с другой стороны, как части
} 
ячейки, которую мы только что выделили. Также понятно, что это «разрастание» открыто для того, что мы называем трансцендентальной интерфактичностью, для потенциального (способного стать актуальным) или виртуального (обречённого воздействовать, не актуализируясь) множества абсолютных здесь. Всё это, равно как и переход от внеязыкового феноменологического схематизма к феноменологическому схематизму языка, ещё нужно будет объяснить.

Допустим для простоты, что внеязыковой феноменологический схематизм

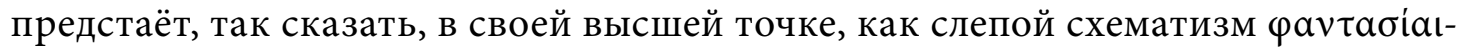
аффектаций, ${ }^{14}$ ритмизованных сгущениями и рассеяниями. Пока возьмем «статическую» перспективу и не будем говорить о схематическом прерывании, а значит и о возвышенном. Тогда мы будем исходить из того, что языковой схематизм состоит в том, чтобы схематическая связь фаvтабía (-аффектации) с pavtaбía (-аффектацией) также была сразу же и «перцептивной» связью (связью «перцептивной» фаvтабía (-аффектации) с «перцептивной» фаvтабía [-аффектацией]). ${ }^{15}$ По крайней мере, из разбора ситуации обмена взглядами,

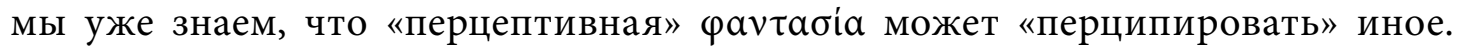
Таким образом, остаётся понять, как эту ситуацию можно обобщить в языке. Предположим, что трансцендентальная интерфактичность - это виртуальное множество абсолютных здесь (а это, по большей части, так). Тогда всякая фаvтабі́ исходит из внеязыкового схематизма; она становится «перцептивной», только когда её, с одной стороны, «перцепируют» в фаvтабі́, а с другой - когда её виртуально осваивают взглядом (таким взглядом, который «перцепировал» ту «перцептивную»

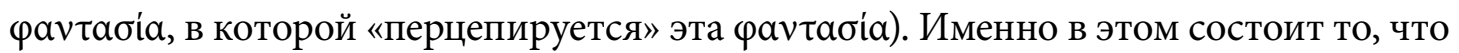
мы называем «рефлексивностью» речевой деятельности.

Речевая деятельность, будь она «одна», была бы лишена ясности, а значит, неотличима от внеязыкового схематизма. Поэтому здесь нужна самость, такая

«объективного мира»), на этой же стадии (стадии чистого Leib) пространство как некая форма ещё не возникает. - Прим. пер.

14 То, что, с нашей точки зрения, всякая фантазия освоена (habitée) аффектацией, мы постарались показать в очерке: «К феноменологии архаических корней аффективности» («Pour une phénoménologie des racines archaïques de l'affectivité») в Annales de phénoménologie, 2004, n³, pp. 155-200 (Richir, 2004, 155-200).

${ }^{15}$ Мы заключаем здесь «аффектацию» в скобки, чтобы указать, что впредь будем опускать это слово, каждый раз его подразумевая. 
самость, которая создаёт смысл и, так сказать, «сопровождает» свою схематизацию. То есть нужно схематическое прерывание и хотя бы скрытое действие функционирующего возвышенного. ${ }^{16}$ Или же самость должна высвободиться в функционирующем возвышенном, чтобы «захватить» ту или иную фаvтабía и освоить (habiter) её. Это нужно для того, чтобы в этом жилище (habitation)

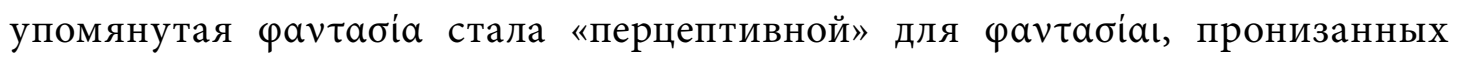
схематизмом. Это также нужно и для того, чтобы в трансцендентальной

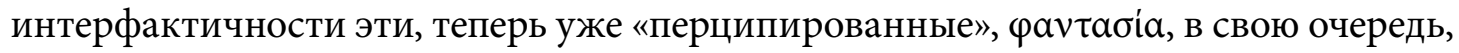

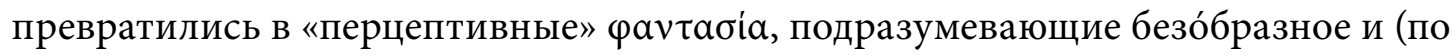
крайней мере виртуально) иные самости. Проблема, при этом, состоит в том, что

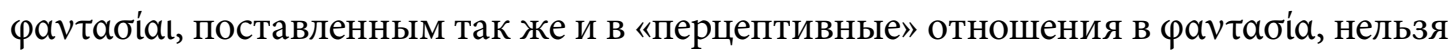
придать вид объектов или даже образов. Они строго предобразны, т. е. подпадают под рубрику a priori неопределённого множества виртуальных изображений (виртуальных, а не потенциальных). Это так, потому что предобразность, которую мы именуем образностью для простоты, не несёт уже в себе их изображений, как и их потенциально возможных актуализаций. Или же это так потому, что эти образности a priori индифферентны к изображениям, способным их зафиксировать. Итак, образность фаvтабі́а,, в этом смысле, виртуальна, но, именно благодаря своей виртуальности, ${ }^{17}$ действенна. И это вполне соответствует тем

\footnotetext{
16 Опыт возвышенного отсылает у Ришира к гиперболической редукции, поскольку в ходе этого опыта, связанного с «дикими смыслами», обнаруживается нечто «изначальное», первородное в человеке. Обнаруживается глубинная аффективная самость, которая составляет одну из главных структур «феноменологического бессознательного». Ришир требует, чтобы в ходе феноменологической редукции мы вышли за пределы «человеческого» - к «внечеловеческому». Поэзия, по его мнению, не вполне справляется с этой задачей, поскольку всё ещё ориентируется на игру «человеческих страстей». Очевидно, под «внечеловеческим» здесь понимается божественное, но рассмотренное не столько в трансцендентном, сколько в трансцендентальном смысле. Возвышение существует на границе, оно является пограничным, т. е. тем, что связывает протоязыковое с языковым. - Прим. пер.

${ }^{17}$ См., например, то, что говорит о лебеде как поэтическом «символе» Гуго фон Гофмансталь, ведущий речь о поэме Геббеля: «[эти лебеди] означают, но не высказывают того, что они означают. Все, что бы ты ни сказал, будет неверно. Они означают здесь не что иное, как самих себя: лебедей. Лебедей, но увиденных глазами поэзии, которая каждый предмет каждый раз видит впервые, которая каждый предмет окружает всеми тайнами своего бытия. Здесь - это величие царственного полета, бесшумное одиночество сияющего белого тела, кружащего по черной воде, печально, высокомерно; чудесная легенда о своем смертном часе... Увиденные такими глазами, звери становятся [...] живыми таинственными шифрами, которыми Бог вписывает в мир неизреченные вещи. Счастлив поэт, которому также дано эти божественные шифры вплетать в свои письмена» (Gofmanstal', 1995, 535). (М. Ришир цитирует французский перевод эссе Гофмансталя по изданию: Hofmannsthal H. von, «L'entretien sur les poèmes
} 
характеристикам фаvтабіa, которые были отмечены Гуссерлем: изменчивому характеру, прерывистости, текучести, молниеносности (blitzhaft) и сущностной мимолетности, затенённости или неясности, как если бы образность не оставила ни места, ни времени изображению. Поэтому данная проблема сопоставима с другой, не менее сложной: не будучи зафиксированной с помощью языковой схематизации, фаvтабía, взятая «в перцепции»в другой фаvтабі́, кажется слишком эфемерной и изменчивой, чтобы играть роль переходного объекта,

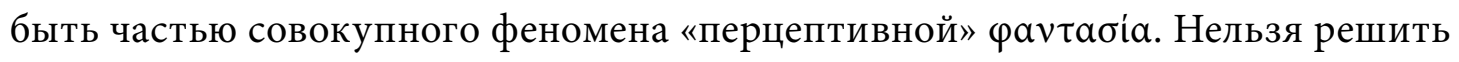
эту проблему, если не допустить, что сама эта переходность виртуальна, т. е. что она действует, но сама по себе, так сказать, не реализуется. Подобным же образом, «перцептивная» фаvтабі́ стороны, подразумевает радикально безо́бразное, благодаря своей виртуальной переходности. С другой стороны, вместе с этим безо́бразным, она подразумевает и совершенно виртуальный взгляд на «перцептивную» фаvтабі́, который её «перцепирует» (совершенно виртуального другого трансцендентальной интерфактичности). В равной степени фаvтабіа подразумевает переходность от

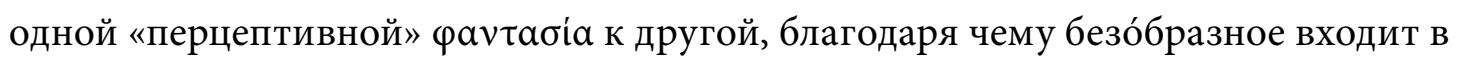
отношение с самим собой - так складывается смысл. И всё это таким образом,

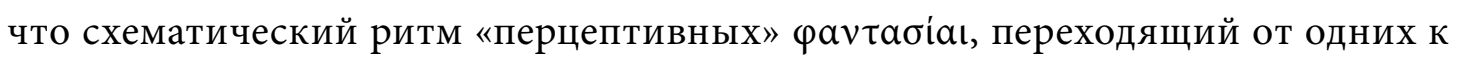
другим, оказывается чем-то вроде следа в зазоре темпорализующего ритма. Это

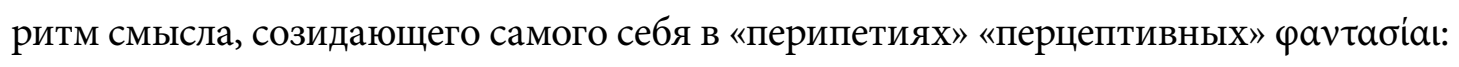
в их поворотах и взаимных метаморфозах в протенциях и ретенциях смысла, движущегося к самому себе (а не к какому-то присутствию, которого там нет).

В свою очередь, этот зазор можно понять лишь в свете того факта, что возвышенное, если оно функционирует, не только сгущает аффективность в сверхплотное ядро аффектаций, образующих самость, но и опустошает, помещая

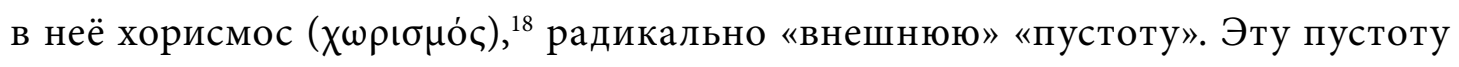

(1903)», in: Hofmannsthal H. von, Lettre de Lord Chandos et autres essais, trad. A. Kohn et J. Cl. Schneider, Paris, Gallimard, 1980, p. 108 (Hofmannsthal, 1980, 180). - Прим. пер.)

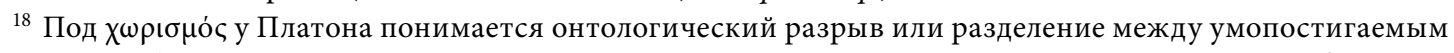

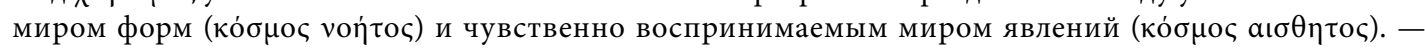
Прим. пер. 
традиционно относят к умопостигаемым элементам; она не принадлежит ни хоре, ни тому или иному «пристанищу» (абсолютному здесь) хоры, ни месту (Leib), ни даже протяжённости. ${ }^{19}$ Пустота не принадлежит и образности; впрочем, это не значит, что она представляет собой умопостигаемое «место» безо́бразного вообще, которое можно без остатка растворить в умопостигаемом (иначе мы имели бы дело с противоречием). Однако с этим радикальным зазором абсолютной трансценденции ещё нужно разобраться; он раскрывает глубину, демонстрируя некое (доступное пониманию) родство между смыслом, созидающим себя в языке, и умопостигаемым. Это - родство, а не тождество (каковым оно было для классической философии). Для такого родства, впрочем, характерно, что и языковой референт в равной степени не растворяется в умопостигаемом; он отличается, сохраняет зазор, не совпадает с языковым смыслом (между ними пролегает бездна). В самом деле, языковой референт a priori конституируется «тем, что» может принимать на себя смысл путем сцепления виртуально образных и виртуально переходных «перцептивных»

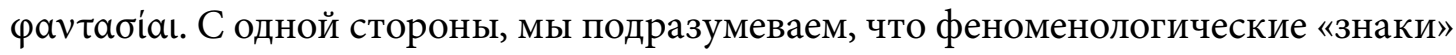
или обрывки смысла не могут смешиваться с ними. С другой стороны, сам смысл темпорализуется (-спациализуется) в промежуточной среде (подобной «среде семантической») между этим абсолютно внешним элементом умопостигаемого и тем, что по отношению к нему, проявляется как интимнейшее внутреннее. Это касается не только самости, но и трансцендентальной интерфактичности как, по меньшей мере, виртуального обмена взглядами («перцептивными»

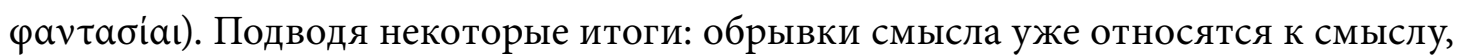

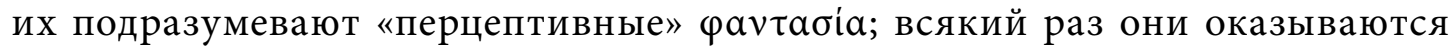
носителями того, что можно было бы назвать зачатками смысла. ${ }^{20}$ Поэтому,

19 Объяснение этих трудных моментов см. в наших Феноменологических фрагментах о времени и пространстве (Fragments phénoménologiques sur le temps et l’espace, éd. Jérôme Millon, Coll. Krisis, Grenoble, 2006) (Richir, 2006).

${ }^{20}$ По поводу этих понятий см. наши Феноменологические размышления (Méditations phénoménologiques, op.cit.) (В данном тексте Ришир говорит о том, что смысл никогда не бывает дан отдельно, но всегда включён в некое смысловое множество, каждый из элементов которого находится в резонансе с другими его элементами. Поэтому «зачатки смысла», ещё до того, как они образовали складки, приводя в действие темпорализацию / спациализацию, не были совершенно формальными или совершенно пустыми, но представляли собой некую феноменологическую конкретность, которая возникает из «обрывков» и «отрезков» двойного мерцательного движения мышления и мысли. Таким образом, смысл для Ришира 
со всей архитектонической строгостью, следует различать обрывок смысла и зачаток смысла: зачатки связаны с множественными и виртуальными смыслами (находящихся между собой в отношениях сверхвозможности (transpossibles) и сверхстрастности (transpassibles) ${ }^{21}$ ), тогда как обрывки всегда уже относятся к возможностям того или иного уже намеченного (amorcé) смысла, т. е. принадлежат ему.

Это крайне парадоксальная ситуация - ситуация самого поэтического элемента, - и её можно обнаружить, например, в центре рилькеанской поэтики. Приведем в качестве «иллюстрации» следующий стих, взятый из поэмы под названием «Гонг»:

«Klang, der, wie ein tieferes Ohr, uns, scheinbar Hörende, hört...»

Т.е. буквально:

«Звук, который, подобно более глубинному слуху, слушает нас, мнимо слушающих...»

Это значит, что наше слушание в действительности представляет собой

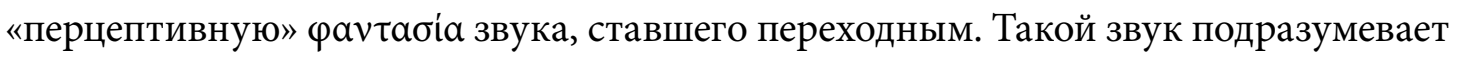
более глубинный слух, он делает нас мнимыми слушателями; скорее это он внимает нам, безо́бразное в нем вслушивается в нас. Таково движение, благодаря которому, «перцептивная» фаvтабі́⿱一⿻上丨 становится движением иной, «перципирующей» её «перцептивной» фаvтабі́ . В нём «перципирующая» самость $\varphi \alpha v \tau a \sigma i \alpha$, уже взятая в «перцептивной» $а \vee \tau \alpha \sigma i \alpha$, перенимается в безо́бразном и рефлексивном характере речевой деятельности. В некотором смысле, благодаря такому выпадению самости как субъекта, именно безо́бразное (у Рильке - дух) как бы «перципирует» себя. Так можно понять то, что Рильке называет поэтическим

инхоативен, т. е. проходит в своём становлении различные «фазы». - Прим. пер.)

${ }^{21}$ См. Мальдине А. О сверхстрастности // Шолохова С.А., Ямпольская А.В. (Пост)феноменология: новая феноменология во Франции и за ее пределами, М.: Академический проект, 2014, C. 145-203 (Mal'dine, 2014, 145-203). - Прим. пер. 
переворотом (или обращением), ${ }^{22}$ где звук «становится» совершенно виртуальным (безо́бразным) другим.

Это позволяет иначе подойти к нашим проблемам. Поэтический переворот, который разрабатывает и разыгрывает Рильке, свойственен не языку (langue), а речевой деятельности (langage). Это так, поскольку он требует поэтической разработки (а не простой риторической игры), которая позволила бы проявиться парадоксу речевой деятельности. Поэтическая разработка делает явным прохождение (transit) смысла через схематическое

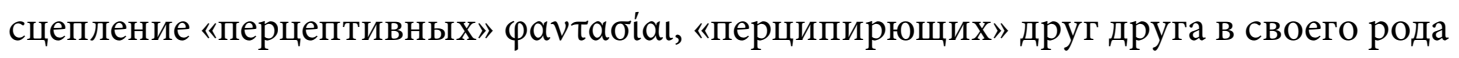
переходной переходности. Ведь вообще «перцептивная» фаvтабі́a подразумевает модификацию в фаvтабía как реального, так и воображаемого. Придание образа этой модификации (в созерцании) делается переходным: образное в ней становится «фиктивным» (даже если есть некий Bildsujet, его квази-полагание само собой «нейтрализуется»), не будучи при этом Bildobjekt (или становясь, в свою очередь, Bildobjekt) некого Bildsujet. Иначе говоря, здесь нет ничего иного, кроме связи переходности и безо́бразного: переходность подразумевает безо́бразное и даёт к нему доступ. Эта связь всякий раз «управляется» свободной игрой, которая странным образом лишена правил, эйдетической обоснованности, и вполне может не проявляться. Во всяком случае, мы встречаемся с этой связью в художественном творчестве и «рецепции», где именно скрытое безо́бразное составляет эстетическое качество. Когда, при схематизации в речевой деятельности, возникает «перцептивная» модификация в Это значит, что $\varphi \alpha v \tau \alpha \sigma i \alpha$, взятая в «перцепции»и не претворённая в образ, может играть переходную роль, только если она виртуальна, через образность,

\footnotetext{
22 Возможно, здесь присутствует скрытая отсылка к «Письмам к молодому поэту» Рильке. Приведем в русском переводе фрагмент из письма Рильке от 19.02.1903, а в скобках хрестоматийный французский перевод. На себя обращают внимание переклички с терминологией Ришира (creuser, retournement etc.): «Углубитесь (rentrez) в себя. [...] Ищите (creusez) в себе глубокого ответа. [...] И если из этого обращения к себе самому (retournement vers l'intérieur), из этого погружения в свой собственный мир родятся стихи, то Вам даже в голову не придет спрашивать кого-нибудь, хорошие ли это стихи». Рильке Р.М. Новые стихотворения, Вторая часть, серия «Литературные памятники», М.: Наука 1977, С. 327-328 (Ril'ke, 1977, 327-328); Rilke R.M. Lettres à un jeune poète, Collection Poésie, Paris: Gallimard, 1993, p. 11 (Rilke, 1993, 11). - Прим. пер.
} 
остающуюся виртуальной, поскольку никакое изображение в принципе не может занять её место. Эта роль играется совершенно незаметно, она действует как своего рода «бессознательная игра». Это подтверждается, с одной стороны, тем,

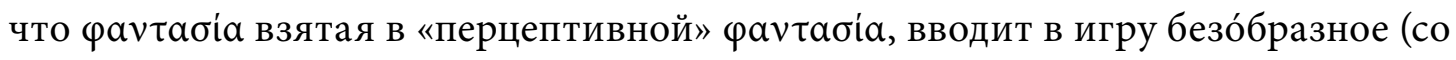
смыслом в зачатке в его же обрывке), которое бы иначе не явилось; с другой стороны, тем, что безо́бразное (такова «ретенция» речевой деятельности) делает обратный ход к воспринимающей его «перцептивной» $\varphi \alpha v \tau \alpha \sigma i \alpha$, выявляя её безо́бразное как носитель иного обрывка смысла, в котором, в свою очередь, скрывается самость. Дело в том, что самость производит не только смысл, но и себя: только так ей доступна рефлексивность, которая никогда просто-напросто не отождествляется с рефлексивностью самости в «моменте» возвышенного. Именно поэтому встаёт новый вопрос, который мы не сможем обсудить здесь: вопрос о модификации в фаvтабіа самости, сгущённой в возвышенном и рефлексирующей себя в «чувстве» возвышенного, в самость, создающую себя при созидании речевой деятельности.

\section{REFERENCES}

Detistova, A. S. (2012). Fenomenologicheskii proekt M. Rishira: fantaziya kak izmerenie fenomenologicheskogo [The Phenomenological Project of M. Richir: Fantasy as a Dimension of the Phenomenological]. Voprosy filosofii [Questions of Philosophy], 6, 139-148. (in Russian).

Platon, (1994). Timei. In Sobranie sochinenii v 4-kh tomakh. T. 3. [Collected Works in 4 Volumes: Vol. 3.]. Moscow: Mysl'. (in Russian).

Hegel G. F. W. (1967). Jenaer Realphilosophie. Vorlesungsmanuskripte zur Philosophie der Natur und des Geistes von 1805-1806. In Hoffmeister, J. (Ed.), Philosophische Bibliothek: Vol 67. Hamburg: Felix Meiner Verlag.

Richir, M. (1992). Méditations phénoménologiques. Grenoble: J. Millon.

Richir, M. (2004). Pour une phénoménologie des racines archaïques de l'affectivité. Annales de phénoménologie, 3, 155-200.

Richir, M. (2006). Fragments phénoménologiques sur le temps et l'espace. Grenoble: J. Millon. 
Richir, M. (2008). Fragments phénoménologiques sur le langage. Grenoble: J. Millon.

Gofmanstal', G. (1995). Razgovor o stikhakh [Conversation about Poems]. In Gofmanstal' G. Izbrannoe: Dramy. Proza. Stikhotvoreniya [Selected Works: Drama. Prose. Poems]. Moscow: Art. (in Russian).

Hofmannsthal, H. (1980). L'entretien sur les poèmes (1903). In Hofmannsthal H. von Lettre de Lord Chandos et autres essays. Paris: Gallimard.

Mal'dine, A. (2014). O sverkhstrastnosti [On Overpassion]. In Sholokhova, S. A., \& Yampol'skaya, A.V (Eds.), (Post)fenomenologiya: novaya fenomenologiya vo Frantsii i za ee predelami [(Post)phenomenology: New Phenomenology in France and Beyond] (145-203). Moscow: Academic Project. (in Russian).

Ril'ke, R. M. (1977). Novye stikhotvoreniya. Seriya Literaturnye pamyatniki [New Poems. Literature Landmarks Series]. Moscow: Nauka. (in Russian).

Rilke, R. M. (1993). Lettres à un jeune poète. In Collection Poésie. Paris: Gallimard. 